\title{
HLA antigens in ocular cicatricial pemphigoid
}

\author{
BARTLY J. MONDINO, STUART I. BROWN, AND BRUCE S. RABIN \\ From the Department of Ophthalmology, University of Pittsburgh School of Medicine and Eye and Ear \\ Hospital, and the Division of Clinical Immunopathology, Department of Pathology, University of \\ Pittsburgh School of Medicine
}

SUMMARY HLA antigen frequencies were studied in 20 patients with ocular cicatricial pemphigoid and 245 normal persons. HLA-B12 demonstrated an increased frequency of $45 \%$ in patients with ocular cicatricial pemphigoid which was statistically significant when compared to a frequency of $19.6 \%$ in the general population $(\mathrm{P}<0.02)$. In patients with ocular cicatricial pemphigoid the prevalence of HLA-A3 was increased to $35 \%$ when compared to $22.9 \%$ in the general population, but this was not statistically significant. The frequency of finding either HLA-A3 or B12 in patients with ocular cicatricial pemphigoid was increased to $75 \%$ in comparison with $38.8 \%$ in the general population $(\mathrm{P}<0 \cdot 005)$. The present study suggests that HLA-B12 and possibly HLA-A3 are genetic markers for ocular cicatricial pemphigoid.

Substantial evidence is accumulating that HLA antigens are correlated with particular disease entities in man (McDevitt and Bodmer, 1974; Dausset and Hors, 1975; Henley and Leopold, 1975; Svejgaard et al., 1975). Many of the diseases associated with HLA antigens are tentatively classified as autoimmune: chronic active hepatitis, multiple sclerosis, myasthenia gravis, Graves's disease, and pemphigus (McDevitt and Bodmer, 1974; Svejgaard et al., 1975). The finding of tissue-fixed immunoglobulins and complement in the conjunctival epithelium and its basement membrane of patients with ocular cicatricial pemphigoid suggests that autoimmune phenomena underlie or are at least associated with this condition (Griffith et al., 1974; Furey et al., 1975; Mondino et al., 1977). Because of these immunopathological features in ocular pemphigoid and because of the postulated linkage of HLA antigens with immune response genes (McDevitt and Bodmer, 1974; Katz and Benacerraf, 1975), histocompatibility antigen testing was performed on 20 patients with ocular pemphigoid to determine if one or more HLA antigens were more prevalent in this population.

\section{Materials and methods}

Twenty unrelated Caucasian patients with the clinical

Address for reprints: Dr Stuart I. Brown, Department of Ophthalmology, Eye and Ear Hospital, 230 Lothrop Street, Pittsburgh, Pennsylvania 15213, USA diagnosis of ocular cicatricial pemphigoid were included in this study. Patients with other causes of conjunctival scarring and shrinkage such as radiation or chemical burns, membranous conjunctivitis, or erythema multiforme were excluded. The control population comprised 245 normal Caucasian individuals from the Pittsburgh area. There was a normal distribution of $\mathrm{ABO}$ blood groups in this population.

HLA tissue typing was performed by lymphocyte cytotoxicity (Amos, 1974). A total of 96 HLA typing sera were employed to define 16 different A-locus antigen specificities and 15 different B-locus antigen specificities. Statistical analysis was performed by the chi-square test with Yates's correction.

\section{Results}

The HLA antigen frequencies in the patient and control groups are presented in Table 1. HLA-B12 showed an increased frequency of $45 \%$ in patients with ocular cicatricial pemphigoid, which was statistically significant when compared with a frequency of $19.6 \%$ in the general population $(P<0.02)$. In the group with ocular cicatricial pemphigoid the prevalence of HLA-A3 was increased to $35 \%$ when compared with $22.9 \%$ in the general population, but this was not statistically significant. The frequency of finding either HLA-A3 or B12 in patients with ocular cicatricial pemphigoid was increased to $75 \%$ in comparison with $38.8 \%$ in the general population $(\mathrm{P}<0.005)$. Only one patient in 
Table 1 Frequencies of $H L A$ antigens

\begin{tabular}{|c|c|c|c|c|}
\hline \multicolumn{3}{|c|}{ General population } & \multicolumn{2}{|c|}{$\begin{array}{l}\text { Ocular cicatricial } \\
\text { Pemphigoid }\end{array}$} \\
\hline \multicolumn{3}{|c|}{ No. $=245$} & \multicolumn{2}{|c|}{ No. $=20$} \\
\hline & No. & $(\%)$ & No. & $(\%)$ \\
\hline A1 & 62 & $(25 \cdot 3)$ & 6 & $(30 \cdot 0)$ \\
\hline A2 & 118 & $(48 \cdot 2)$ & 10 & $(50.0)$ \\
\hline A3 & 56 & (22.9) & 7 & $(35.0)^{*}$ \\
\hline A9 & 37 & $(15 \cdot 1)$ & 4 & $(20.0)$ \\
\hline A10 & 19 & $(7 \cdot 8)$ & 2 & $(10.0)$ \\
\hline A11 & 27 & $(11 \cdot 0)$ & 0 & - \\
\hline A28 & 20 & $(8 \cdot 2)$ & 2 & $(10 \cdot 0)$ \\
\hline A29 & 7 & $(2.9)$ & 1 & $(5 \cdot 0)$ \\
\hline AW23 & 5 & $(2 \cdot 0)$ & 0 & - \\
\hline AW24 & 21 & $(8.6)$ & 2 & $(10 \cdot 0)$ \\
\hline AW25 & 6 & $(2 \cdot 4)$ & 0 & - \\
\hline AW26 & 4 & $(1 \cdot 6)$ & 0 & - \\
\hline AW30 & 22 & $(9.0)$ & 0 & - \\
\hline AW31 & 8 & $(3 \cdot 3)$ & 2 & $(10 \cdot 0)$ \\
\hline AW32 & 13 & $(5 \cdot 3)$ & 0 & - \\
\hline AW33 & 2 & $(0.8)$ & 0 & - \\
\hline B5 & 24 & (9.8) & 0 & - \\
\hline B7 & 41 & $(16 \cdot 7)$ & 6 & $(30.0)^{*}$ \\
\hline B8 & 48 & $(19 \cdot 6)$ & 3 & $(15.0)$ \\
\hline B12 & 48 & $(19 \cdot 6)$ & 9 & $(45 \cdot 0) \dagger$ \\
\hline B13 & 19 & (7.8) & 0 & - \\
\hline B15 & 12 & (4.9) & 1 & $(5 \cdot 0)$ \\
\hline B18 & 30 & $(12 \cdot 2)$ & 2 & $(10.0)$ \\
\hline B27 & 20 & $(8 \cdot 2)$ & 2 & $(10.0)$ \\
\hline BW15 & 24 & $(9.8)$ & 0 & - \\
\hline BW16 & 14 & $(5 \cdot 7)$ & 2 & $(10 \cdot 0)$ \\
\hline BW17 & 23 & $(9 \cdot 4)$ & 1 & $(5 \cdot 0)$ \\
\hline BW21 & 14 & $(5 \cdot 7)$ & 0 & - \\
\hline BW22 & 5 & $(2.0)$ & 0 & - \\
\hline BW35 & 66 & (26.9) & 3 & $(15 \cdot 0)$ \\
\hline BW40 & 32 & $(13 \cdot 1)$ & 4 & $(20.0)$ \\
\hline \multicolumn{5}{|c|}{ Either B12 } \\
\hline or $\mathrm{A} 3$ & 95 & $(38 \cdot 8)$ & 15 & $(75 \cdot 0) \ddagger$ \\
\hline
\end{tabular}

* Not significant.

$+\chi^{2}=5 \cdot 64, P<0.02$ as compared to general population (Yates's corrected chi-square test).

$\ddagger \chi^{2}=8.55, P<0.005$ when compared to general population (Yates's corrected chi-square test).

the pemphigoid series had both the HLA-A3 and B12 antigens.

\section{Discussion}

To date, several HLA antigens have been associated with ocular disease. HLA-B27 has been associated with Reiter's syndrome and acute anterior uveitis (McDevitt and Bodmer, 1974; Henley and Leopold, 1975; Svejgaard et al., 1975), HLA-B5 with Behçet's disease (Ohno et al., 1975), HLA-BW22J with VogtKoyanagi-Harada syndrome (Tagawa et al., 1976), and HLA-A3, B7, and B12 with primary open-angle glaucoma (Becker and Shin, 1977; Shin et al., 1977).

The present study revealed an increased frequency of HLA-B12 and A3 in 20 unrelated patients with ocular cicatricial pemphigoid. This was statistically significant, however, only in the case of HLA-B12 $(P<0.02)$. This study also showed that $75 \%$ of patients with ocular cicatricial pemphigoid had either HLA-A3 or B12, and that this prevalence was statistically significant when compared with $38.8 \%$ in the general population $(P<0.005)$. This latter finding suggests that, as additional patients are studied with ocular cicatricial pemphigoid, an increased frequency of HLA-A3 in itself will be statistically demonstrated. There does not appear to be a linkage disequilibrium between HLA-A3 and B12 in patients with ocular cicatricial pemphigoid, since only 1 patient possessed both antigens.

There is also an increased prevalence of HLA-B12 in patients with primary open-angle glaucoma and HLA-A3 in white patients with primary open-angle glaucoma (Becker and Shin, 1977; Shin et al., 1977). The finding that an HLA antigen is associated with multiple diseases is not without precedent. HLAB27 has been associated with ankylosing spondylitis, Reiter's disease, and acute anterior uveitis, while HLA-B8 is correlated with Graves's disease, myasthenia gravis, chronic hepatitis, and dermatitis herpetiformis (McDevitt and Bodmer, 1974; Svejgaard et al., 1975). HLA-A3 and B7 have been associated with multiple sclerosis in addition to primary open-angle glaucoma (McDevitt and Bodmer, 1974; Svejgaard et al., 1975).

None of the patients with ocular cicatricial pemphigoid in this series had evidence of primary open-angle glaucoma. Intraocular pressure determinations on numerous occasions by Goldmann tonometry and Alcon pneumo-tonometry were all normal except for 2 patients who developed secondary glaucoma attributable to extensive anterior and posterior synechiae following repair of corneal perforations. Photophobia together with extensive corneal scarring and vascularisation precluded reliable visual field testing in the majority of patients.

The results of the present study suggest that HLAB12 and possibly HLA-A3 are genetic markers for ocular cicatricial pemphigoid.

\section{References}

Amos, B. (1974). HLA typing cytotoxicity test. In Ray, J. G., Hare, D. R., Pedersen, P. D., and Kayhoe, D. E. (eds): Manual of Tissue Typing Techniques. Department of Health, Education and Welfare Publication No. 75-545, pp. 23-26.

Becker, B., and Shin, D. H. (1977). HLA antigens and primary open-angle glaucoma in black Americans. Investigative Ophthalmology, 16, 175-176.

Dausset, J., Hors, J. (1975). Some contributions of the HL-A Complex to the genetics of human diseases. Transplantation Review, 22, 44-72.

Furey, N., West, C., Andrews, T., Paul, P. D., and Bean, S. F. (1975). Immunofluorescent studies of ocular cicatricial pemphigoid. American Journal of Ophthalmology, 80, 825-831.

Griffith, M. R., Fukuyama, K., Tuffanelli, D., and Silverman, 
S. (1974). Immunofluorescent studies in mucous membrane pemphigoid. Archives of Dermatology, 108, 195-199.

Henley, W. L., and Leopold, I. H. (1975). Importance of HL-A antigens in Ophthalmology. American Journal of Ophthalmology, 80, 774-778.

Katz, D. H., and Benacerraf, B. (1975). The function and interrelationships of T-cell receptors, Ir genes and other histocompatibility gene products. Transplantation Review, 22, 175-193.

McDevitt, H. O., and Bodmer, W. F. (1974). HL-A, Immune response genes, and disease. Lancet, 1, 1269-1275.

Mondino, B. J., Ross, A. N., Rabin, B. S., and Brown, S. I. (1977). Autoimmune phenomena in ocular cicatricial pemphigoid. American Journal of Ophthalmology, 83, 443-450.
Ohno, S., Nakayama, E. Sugiura, S., Itakura, K., Aoki, K., and Aizawa, M. (1975). Specific histocompatibility antigens associated with Behcet's disease. American Journal of Ophthalmology, 80, 636-641.

Shin, D. H., Becker, B., Waltman, S. R., Palmberg, P. F., and Bell, C. E. (1977). The prevalence of HLA-B12 and HLA-B7 antigens in primary open-angle glaucoma. Archives of Ophthalmology, 95, 224-225.

Svejgaard, A., Platz, P., Ryder, L. P., Nielsen, L. S., and Thomsen, M. (1975). HL-A and disease associations-a survey. Transplantation Review, 22, 3-43.

Tagawa, Y., Sugiura, S., Yakura, H., Wakisaka, A., Aizawa, M., and Itakura, K. (1976). HLA and Vogt-KoyanagiHarada Syndrome. New England Journal of Medicine, 297, 173. 